\title{
Visit-to-Visit Variability and Seasonal Variation in Blood Pressure With Single-Pill Fixed-Dose Combinations of Angiotensin II Receptor Blocker/Calcium Channel Blocker and Angiotensin II Receptor Blocker/Diuretic in Hypertensive Patients
}

\author{
Yuhei Shiga ${ }^{a}$, Shin-ichiro Miura ${ }^{a}$ b, c, Sen Adachi ${ }^{a}$, Yasunori Suematsu ${ }^{a}$, Makoto Sugihara ${ }^{a}$, \\ Atsushi Iwata ${ }^{a}$, Eiji Yahiro ${ }^{a}$, Hiroaki Nishikawa ${ }^{a}$, Masahiro Ogawa ${ }^{a}$, Keijiro Saku ${ }^{\text {a }}$ b
}

\begin{abstract}
Background: The visit-to-visit variability in blood pressure (BP) has been shown to be a strong predictor of cardiovascular events. It is not known whether anti-hypertensive therapy using a single-pill fixeddose combination of angiotensin II receptor blocker (ARB)/calcium channel blocker (CCB) or ARB/diuretic (DI) in hypertensive patients affects the visit-to-visit variability and seasonal variation of BP.

Methods: We enrolled 47 hypertensive patients who had received a single-pill fixed-dose combination of either ARB/CCB $(n=30)$ or $\mathrm{ARB} / \mathrm{DI}(\mathrm{n}=17)$ for 15 months. Beginning 3 months after the start of $\mathrm{ARB} / \mathrm{CCB}$ or $\mathrm{ARB} / \mathrm{DI}$ treatment, we determined the visit-to-visit variability in $\mathrm{BP}$ expressed as the standard deviation (SD) of average $\mathrm{BP}$ and the seasonal variation in $\mathrm{BP}$ expressed as the SD of average $\mathrm{BP}$ in each season (spring, summer, fall and winter were defined as lasting from March to May, June to August, September to November and December to February, respectively) for a year.
\end{abstract}

Results: There were no significant differences in baseline patient characteristics except for the prevalence of coronary artery disease and the percentage of $\mathrm{CCB}$ excluding amlodipine in the $\mathrm{ARB} / \mathrm{CCB}$ group between the $\mathrm{ARB} / \mathrm{CCB}$ and $\mathrm{ARB} / \mathrm{DI}$ groups. There were no significant differences in the 1-year time course of systolic and diastolic BP (SBP and DBP) between the groups, although there were significant differences in SBP in August and November and DBP in December. Interestingly, the visit-to-visit variability and seasonal variation of $\mathrm{BP}$ in the $\mathrm{ARB} / \mathrm{CCB}$ group were similar to those in the ARB/DI group.

Manuscript accepted for publication August 11, 2015

aDepartment of Cardiology, Fukuoka University School of Medicine, Fukuoka, Japan

${ }^{b}$ Department of Molecular Cardiovascular Therapeutics, Fukuoka University School of Medicine, Fukuoka, Japan

${ }^{\mathrm{c} C o r r e s p o n d i n g ~ A u t h o r: ~ S h i n-i c h i r o ~ M i u r a, ~ D e p a r t m e n t ~ o f ~ C a r d i o l o g y, ~ F u k u o-~}$ ka University School of Medicine, 7-45-1 Nanakuma, Jonan-ku, Fukuoka 814-0180, Japan.Email: miuras@cis.fukuoka-u.ac.jp

doi: http://dx.doi.org/10.14740/jocmr2292w
Conclusion: Single-pill fixed-dose combinations of $\mathrm{ARB} / \mathrm{CCB}$ and $\mathrm{ARB} / \mathrm{DI}$ had similar effects on visit-to-visit variability and seasonal variation in $\mathrm{BP}$ in hypertensive patients.

Keywords: Visit-to-visit variability; Seasonal variation; Blood pressure

\section{Introduction}

The visit-to-visit variability in blood pressure (BP) has been shown to be a strong predictor of cardiovascular disease (CVD), stroke and mortality independent of BP per se [1-5]. The 24-h means and standard deviations (SDs) (i.e., variabilities) of systolic BP (SBP), mean BP and diastolic BP (DBP) have been shown to be related to the rate and severity of targetorgan damage [6]. In addition, seasonal differences in BP are important in the treatment of hypertensive patients. Generally, $\mathrm{BP}$ is lower in hot months than in cold months [7], and CVD mortality and morbidity peak in the winter.

Although optimal BP control is associated with remarkable clinical benefits with regard to $\mathrm{CV}$ and renal protection, many patients still show higher BP. Most patients with hypertension (HTN) require two or more drugs to achieve their target BP [8]. Various guidelines recommend the use of combinations of angiotensin II receptor blockers (ARBs) and calcium channel blockers (CCBs) or diuretics (DIs) [9, 10]. However, there is still some controversy regarding which single-pill fixed-dose combinations of $\mathrm{ARB} / \mathrm{CCB}$ or $\mathrm{ARB} / \mathrm{DI}$ are effective for the treatment of HTN.

Clinicians are often obliged to reduce the dosage of antihypertensive drugs, especially DIs, in summer to avoid excessive BP lowering. We hypothesized that a combination of ARB and CCB would have a more beneficial effect on the visit-tovisit variability and seasonal variation in $\mathrm{BP}$ than a combination of ARB and DI. Therefore, we investigated the visit-tovisit variability and seasonal variation in BP in patients with HTN who had received a single-pill fixed-dose combination of either $\mathrm{ARB} / \mathrm{CCB}$ or $\mathrm{ARB} / \mathrm{DI}$. 
Table 1. Baseline Characteristics in the ARB/CCB and ARB/ DI Groups

\begin{tabular}{|lll|}
\hline & $\begin{array}{l}\text { ARB/CCB } \\
(\mathbf{n}=\mathbf{3 0})\end{array}$ & $\begin{array}{l}\text { ARB/DI } \\
(\mathbf{n}=\mathbf{1 7})\end{array}$ \\
\hline Age, years & $70 \pm 10$ & $68 \pm 10$ \\
\hline Male, \% & 60 & 59 \\
\hline BMI, $\mathrm{kg} / \mathrm{m}^{2}$ & $25 \pm 3$ & $24 \pm 3$ \\
\hline $\mathrm{DM}, \%$ & 13 & 6 \\
\hline $\mathrm{DL}, \%$ & 57 & 76 \\
\hline $\mathrm{CAD}, \%$ & 17 & $47^{*}$ \\
\hline Medications & & \\
\hline \multicolumn{1}{c}{ CCB, \% } & 7 & $59^{*}$ \\
\hline DI, \% & 13 & 0 \\
\hline$\alpha \beta$ blocker, \% & 7 & 12 \\
\hline$\beta$ blocker, \% & 17 & 24 \\
\hline Aldosterone antagonist, $\%$ & 7 & 12 \\
\hline
\end{tabular}

Continuous variables are expressed as mean \pm SD. ARB: angiotensin II receptor blocker; CCB: calcium channel blocker; DI: diuretic; BMI: body mass index; DM: diabetes mellitus; DL: dyslipidemia; CAD: coronary artery disease. \%CCB in the ARB/CCB group and \%DI in the ARB/DI group indicate the percentages of $\mathrm{CCB}$ except for amlodipine and $\mathrm{DI}$ except for hydrochlorothiazide, respectively. ${ }^{*} \mathrm{P}<0.05 \mathrm{vs}$. ARB/CCB.

\section{Methods}

\section{Study patients}

We enrolled 47 hypertensive patients who received a singlepill fixed-dose combination of either telmisartan $40 \mathrm{mg} /$ day + amlodipine $5 \mathrm{mg} /$ day (MicamloAP $\left.{ }^{\circledR}\right)(\mathrm{n}=30, \mathrm{ARB} / \mathrm{CCB}$ group) or telmisartan $40 \mathrm{mg}$ /day + hydrochlorothiazide 12.5 mg/day (MicombiAP $\left.{ }^{\circledR}\right)(n=17, A R B / D I$ group), and did not change these anti-hypertensive drugs for 15 months. The subjects were aged 20 years or older (no upper limit of age). The protocol in this study was approved by the ethics committee of Fukuoka University Hospital, and we retrospectively collected all of the data and performed a post hoc analysis using the database of Fukuoka University Hospital.

\section{Patient characteristics}

The characteristics of the patients, with regard to history of dyslipidemia (DL), diabetes mellitus (DM), coronary artery disease (CAD) and medication use, were obtained from medical records. Patients with $\mathrm{LDL}-\mathrm{C} \geq 140 \mathrm{mg} / \mathrm{dL}, \mathrm{TG} \geq 150 \mathrm{mg} /$ $\mathrm{dL}$, and/or HDL-C $<40 \mathrm{mg} / \mathrm{dL}$, or who were receiving lipidlowering therapy, were considered to have DL. DM was defined using the Japanese Diabetes Society criteria or the use of a glucose-lowering drug. CAD (stable angina) was defined as no changes in the frequency, duration, or intensity of symptoms for 4 weeks and as lumen diameter stenosis $>50 \%$ by coronary angiography in at least one major coronary artery. Body mass index (BMI) was calculated as weight $/$ height $\left(\mathrm{kg} / \mathrm{m}^{2}\right)$.

\section{Measurement of $\mathrm{BP}$ and pulse rate (PR)}

BP was determined as the mean of two measurements obtained in an office setting by the conventional cuff method using a mercury sphygmomanometer after at least $5 \mathrm{~min}$ of rest. Office SBP, DBP and PR measurements were obtained every clinic visit at a 1 - to 2-month interval for 15 months. Beginning 3 months after the start of $\mathrm{ARB} / \mathrm{CCB}$ or $\mathrm{ARB} / \mathrm{DI}$ treatment, we determined the visit-to-visit variability in $\mathrm{BP}$ or PR expressed as the SD of the average BP or PR and the seasonal variation in $\mathrm{BP}$ or PR expressed as the $\mathrm{SD}$ of the average $\mathrm{BP}$ or PR in each season for the next 12 months. Spring, summer, fall and winter were defined as lasting from March to May, June to August, September to November, and December to February, respectively, in Japan.

\section{Statistical analysis}

Statistical analysis was performed using the Stat View statistical software package (Stat View 5; SAS Institute Inc., Cary, $\mathrm{NC}$, USA). Data are shown as the mean \pm SD. Categorical and continuous variables were compared between the groups by a Chi-square analysis and unpaired $t$-test, respectively. One-way analysis of variance was used to compare time course changes in $\mathrm{BP}$ and $\mathrm{PR}$ between the $\mathrm{ARB} / \mathrm{CCB}$ and $\mathrm{ARB} / \mathrm{DI}$ groups. $\mathrm{A}$ value of $\mathrm{P}<0.05$ was considered significant.

\section{Results}

\section{Patient characteristics at baseline}

Table 1 shows the characteristics in the ARB/CCB and ARB/ DI groups. There were significant differences in $\% \mathrm{CAD}$ and $\% \mathrm{CCB}$ excluding amlodipine in the $\mathrm{ARB} / \mathrm{CCB}$ group amlodipine between the $\mathrm{ARB} / \mathrm{CCB}$ and $\mathrm{ARB} / \mathrm{DI}$ groups. The $\% \mathrm{CAD}$ in the $A R B / D I$ group was significantly higher than that in the $\mathrm{ARB} / \mathrm{CCB}$ group.

\section{Time courses of BP and PR in each month for 12 months}

The time courses of BP and PR in each month for 12 months are shown in Figure 1. Although SBP in August and November, DBP in December and PR in May in the ARB/CCB group were significantly higher than those in the ARB/DI group, there were no differences in the 1-year time courses of BP and PR between the groups.

\section{Time courses of BP and PR in each season for 12 months}

The time courses of BP and PR in each season for 12 months 
A. BP

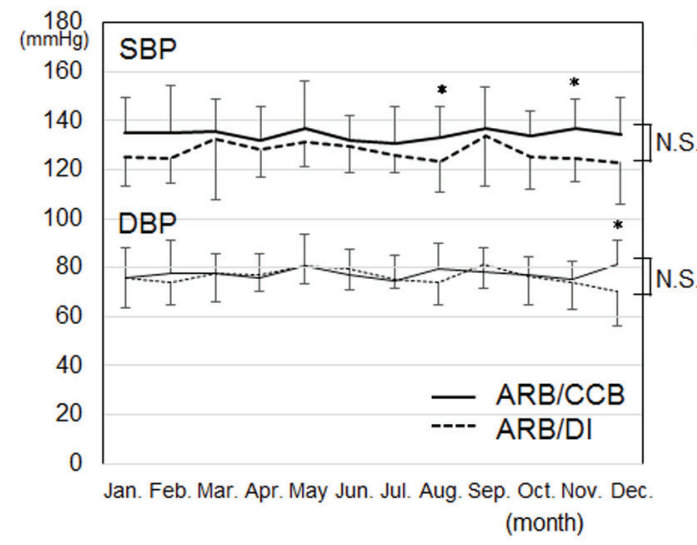

B. PR

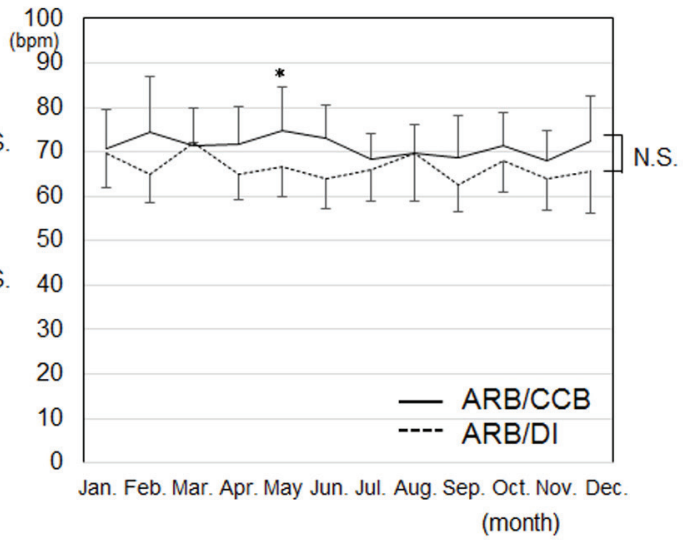

Figure 1. Time courses of blood pressure (BP) $(A)$ and pulse rate $(P R)(B)$ in each month for 12 months in the $A R B / C C B$ and ARB/DI groups. * $P<0.05$ vs. ARB/DI group. NS: not significant.

are shown in Figure 2. There were no differences in the seasonal time courses of BP and PR in each season between the groups.

\section{Visit-to-visit variability and seasonal variation of BP and PR}

There were no differences in the visit-to-visit variability of BP and PR, as shown in Figure 3. In addition, there were no differences in the seasonal variation of $\mathrm{BP}$ and $\mathrm{PR}$, as shown in Figure 4.

\section{Discussion}

In this retrospective study, we assessed the visit-to-visit variability and seasonal variation of $\mathrm{BP}$ and $\mathrm{PR}$ in patients with
HTN who had received a single-pill fixed-dose combination of either $\mathrm{ARB} / \mathrm{CCB}$ or ARB/DI. First, we found that single-pill fixed-dose combinations of $\mathrm{ARB} / \mathrm{CCB}$ and $\mathrm{ARB} / \mathrm{DI}$ similarly affected the visit-to-visit variability of $B P$ and $P R$ in hypertensive patients. Second, there was no difference in the seasonal variation between $\mathrm{ARB} / \mathrm{CCB}$ and $\mathrm{ARB} / \mathrm{DI}$.

The most interesting finding was that $\mathrm{ARB} / \mathrm{CCB}$ and $\mathrm{ARB} / \mathrm{DI}$ similarly affected the visit-to-visit variability of $\mathrm{BP}$. At the beginning of the study, we hypothesized that the combination of $\mathrm{ARB} / \mathrm{CCB}$ would have a more beneficial effect on the visit-to-visit variability of BP than the combination of $\mathrm{ARB} / \mathrm{DI}$, since an increase in the visit-to-visit variability of BP may be explained in terms of arterial stiffness and abnormal autonomic function $[11,12]$. In addition, CCB reduced the interindividual variability of SBP more than non-dihydropyridine CCB, non-loop DI, ARB, angiotensin converting enzyme inhibitor, $\alpha_{1}$-blocker and $\beta$-blocker [13]. Combination therapy with $\mathrm{ARB} / \mathrm{CCB}$ may be preferable to that with $\mathrm{ARB} / \mathrm{DI}$ for
A. BP

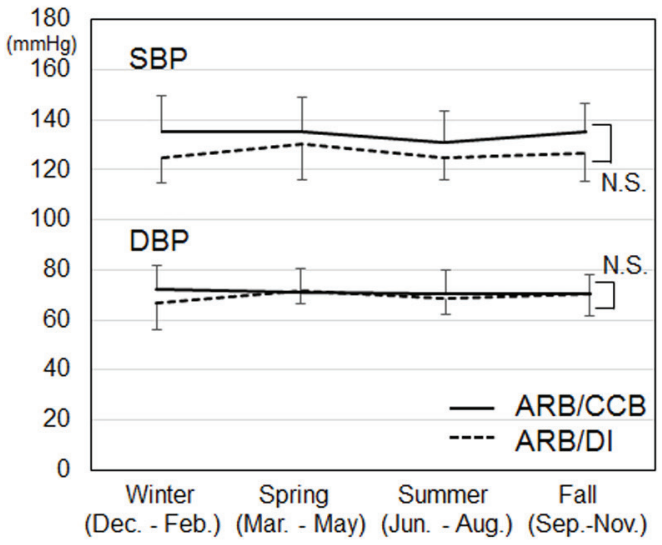

B. PR

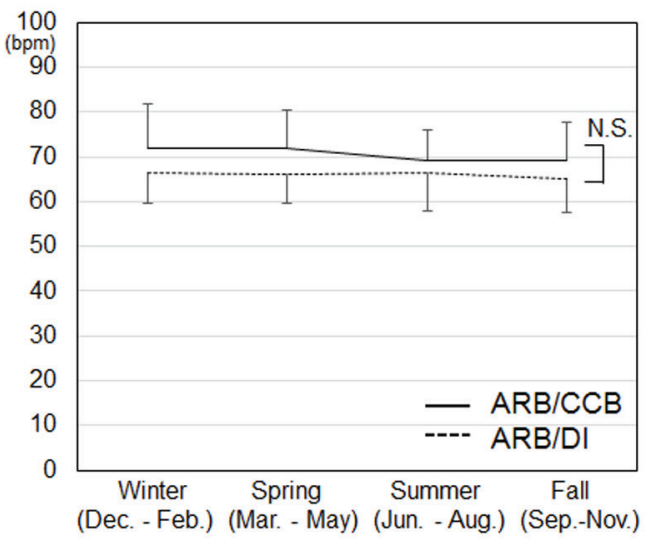

Figure 2. Time courses of systolic and diastolic blood pressure (SBP and DBP) (A) and pulse rate (PR) (B) in each season for 12 months. ${ }^{*} \mathrm{P}<0.05$ vs. ARB/DI group. NS: not significant. 
A. SBP

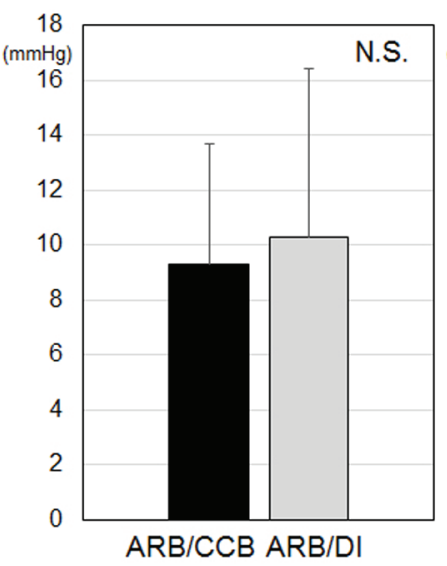

B. DBP

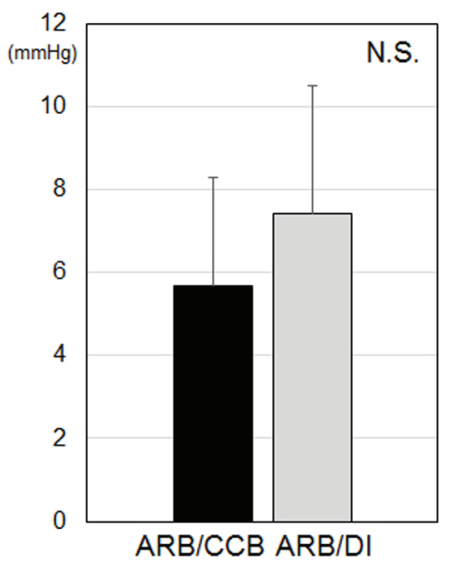

C. PR

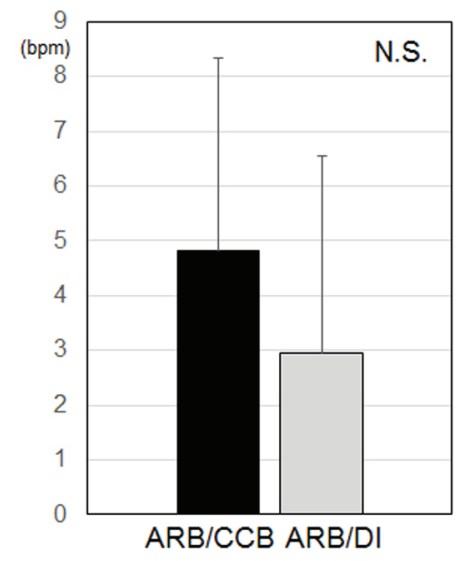

Figure 3. Visit-to-visit variabilities of systolic blood pressure (SBP) (A), diastolic BP (DBP) (B) and pulse rate (PR) (C). NS: not significant.

decreasing the visit-to-visit variability of BP [14]. There are several reasons why our results did not support our hypothesis. According to the Japanese Society of Hypertension Guidelines for the Management of Hypertension (JSH2014), the target in BP control should be $<140 / 90 \mathrm{~mm} \mathrm{Hg}$ [9]. Since almost all of the patients in this study achieved the target BP, there were no differences in the visit-to-visit variability of BP. Moreover, a high visit-to-visit variability of $\mathrm{BP}$ is associated with cardiac diastolic function independent of mean BP [15]. Since all of the patients had HTN in this study and HTN first influences diastolic function, the differential effect in visit-to-visit variability of BP between the ARB/CCB and ARB/DI groups is not clearly seen. Moreover, since $59 \%$ of patients in the ARB/ DI group were receiving $\mathrm{CCB}$, it may also affect the visit-tovisit variability of BP.

Second, we thought that the combination of $\mathrm{ARB} / \mathrm{CCB}$ would have a more beneficial effect on the seasonal variation of BP than the combination of ARB/DI because the dose of DI needs to be reduced in the summer to avoid excessive BP lowering due to dehydration. In addition, since a colder ambient temperature leads to higher BP [16] and high dietary salt intake potentiates the cold-induced increase in BP [17], DI may have a greater effect on the seasonal variation in BP than CCB. Interestingly, there were no differences in the seasonal variation of $\mathrm{BP}$ between the ARB/CCB and ARB/DI groups. The combination of $A R B / D I$ could be used safely throughout the year.

There were no differences in the visit-to-visit variability or the seasonal variation of PR between the ARB/CCB and $\mathrm{ARB} / \mathrm{DI}$ groups. Heart rate variability, a measure of autonomic dysfunction, has been associated with an increased risk of myocardial ischemia in patients with cardiovascular disease [18]. Although \%CAD in the ARB/DI group was significantly higher than that in the $\mathrm{ARB} / \mathrm{CCB}$ group, the combination of ARB/DI may be relatively safe in patients with CAD.

This study has several limitations. First, this study was retrospective and included a small number of patients. Second,
A. SBP

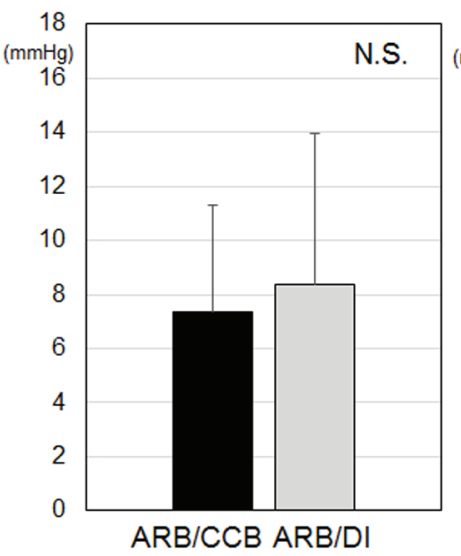

B. DBP

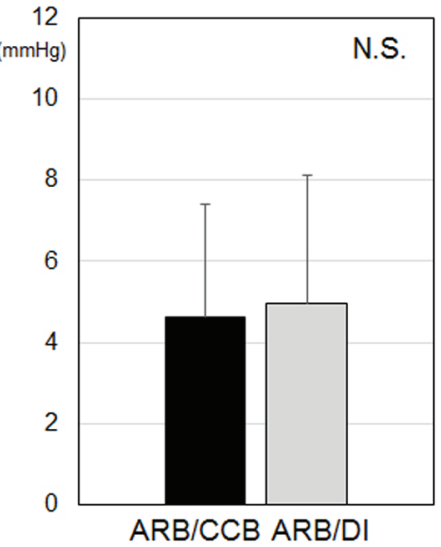

C. PR

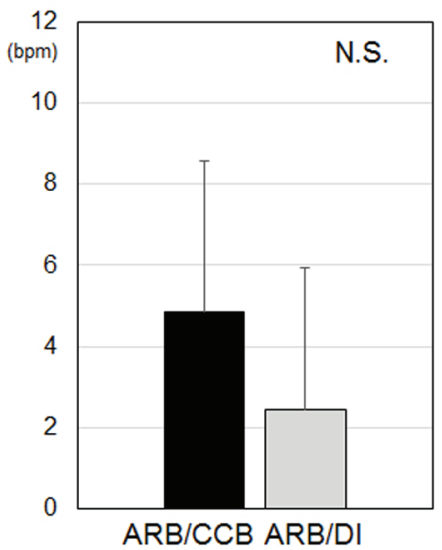

Figure 4. Seasonal variations of systolic blood pressure (SBP) (A), diastolic BP (DBP) (B) and pulse rate (PR) (C). NS: not significant. 
the analysis was performed after other various anti-hypertensive treatments in addition to a combination of $\mathrm{ARB} / \mathrm{CCB}$ or ARB/DI. Third, we measured BP and PR for only 1 year and did not evaluate the clinical outcome. Prospective long-term studies are needed to clarify these limitations.

In conclusion, single-pill fixed-dose combinations of $\mathrm{ARB} / \mathrm{CCB}$ and $\mathrm{ARB} / \mathrm{DI}$ had similar effects on the visit-tovisit variability and seasonal variation in $\mathrm{BP}$ in hypertensive patients.

\section{Funding}

None.

\section{Conflicts of Interest}

K.S. is a Chief Director and S.M. is a Director of NPO Clinical and Applied Science, Fukuoka, Japan. K.S. has an Endowed "Department of Molecular Cardiovascular Therapeutics" supported by MSD, Co. Ltd. S.M. belongs to the Department of Molecular Cardiovascular Therapeutics, which is supported by MSD, Co. Ltd.

\section{References}

1. Hata Y, Muratani H, Kimura Y, Fukiyama K, Kawano Y, Ashida T, Yokouchi M, et al. Office blood pressure variability as a predictor of acute myocardial infarction in elderly patients receiving antihypertensive therapy. J Hum Hypertens. 2002;16(2):141-146.

2. Hastie CE, Jeemon P, Coleman H, McCallum L, Patel R, Dawson J, Sloan W, et al. Long-term and ultra long-term blood pressure variability during follow-up and mortality in 14,522 patients with hypertension. Hypertension. 2013;62(4):698-705.

3. Muntner P, Shimbo D, Tonelli M, Reynolds K, Arnett DK, Oparil S. The relationship between visit-to-visit variability in systolic blood pressure and all-cause mortality in the general population: findings from NHANES III, 1988 to 1994. Hypertension. 2011;57(2):160-166.

4. Rothwell PM, Howard SC, Dolan E, O'Brien E, Dobson JE, Dahlof B, Sever PS, et al. Prognostic significance of visitto-visit variability, maximum systolic blood pressure, and episodic hypertension. Lancet. 2010;375(9718):895-905.

5. Diaz KM, Tanner RM, Falzon L, Levitan EB, Reynolds K, Shimbo D, Muntner P. Visit-to-visit variability of blood pressure and cardiovascular disease and all-cause mortality: a systematic review and meta-analysis. Hypertension. 2014;64(5):965-982.

6. Parati G, Pomidossi G, Albini F, Malaspina D, Mancia G. Relationship of 24-hour blood pressure mean and variability to severity of target-organ damage in hypertension. J Hypertens. 1987;5(1):93-98.

7. Sega R, Cesana G, Bombelli M, Grassi G, Stella ML,
Zanchetti A, Mancia G. Seasonal variations in home and ambulatory blood pressure in the PAMELA population. Pressione Arteriose Monitorate E Loro Associazioni. J Hypertens. 1998;16(11):1585-1592.

8. Dahlof B, Sever PS, Poulter NR, Wedel H, Beevers DG, Caulfield M, Collins R, et al. Prevention of cardiovascular events with an antihypertensive regimen of amlodipine adding perindopril as required versus atenolol adding bendroflumethiazide as required, in the Anglo-Scandinavian Cardiac Outcomes Trial-Blood Pressure Lowering Arm (ASCOT-BPLA): a multicentre randomised controlled trial. Lancet. 2005;366(9489):895-906.

9. Ogihara T, Kikuchi K, Matsuoka H, Fujita T, Higaki J, Horiuchi M, Imai Y, et al. The Japanese Society of Hypertension Guidelines for the Management of Hypertension (JSH 2009). Hypertens Res. 2009;32(1):3-107.

10. Mancia G, De Backer G, Dominiczak A, Cifkova R, Fagard R, Germano G, Grassi G, et al. 2007 Guidelines for the Management of Arterial Hypertension: The Task Force for the Management of Arterial Hypertension of the European Society of Hypertension (ESH) and of the European Society of Cardiology (ESC). J Hypertens. 2007;25(6):11051187.

11. Imai Y, Aihara A, Ohkubo T, Nagai K, Tsuji I, Minami N, Satoh H, et al. Factors that affect blood pressure variability. A community-based study in Ohasama, Japan. Am J Hypertens. 1997;10(11):1281-1289.

12. Palatini $\mathrm{P}$, Julius $\mathrm{S}$. The role of cardiac autonomic function in hypertension and cardiovascular disease. Curr Hypertens Rep. 2009;11(3):199-205.

13. Webb AJ, Fischer U, Mehta Z, Rothwell PM. Effects of antihypertensive-drug class on interindividual variation in blood pressure and risk of stroke: a systematic review and meta-analysis. Lancet. 2010;375(9718):906-915.

14. Sato N, Saijo Y, Sasagawa Y, Morimoto H, Takeuchi T, Sano H, Koyama S, et al. Visit-to-visit variability and seasonal variation in blood pressure: Combination of Antihypertensive Therapy in the Elderly, Multicenter Investigation (CAMUI) Trial subanalysis. Clin Exp Hypertens. 2015;37(5):411-419.

15. Okada R, Okada A, Okada T, Nanasato M, Wakai K. Visitto-visit blood pressure variability is a marker of cardiac diastolic function and carotid atherosclerosis. BMC Cardiovasc Disord. 2014;14:188.

16. Brook RD, Weder AB, Rajagopalan S. "Environmental hypertensionology" the effects of environmental factors on blood pressure in clinical practice and research. J Clin Hypertens (Greenwich). 2011;13(11):836-842.

17. Arjamaa O, Turunen L, Makinen T, Laitinen J, Leppaluoto J, Vuolteenaho O, Rintamaki H. Blood pressure and hormonal responses to short whole body cold exposure in subjects with high dietary salt intake. Appl Human Sci. 1999;18(6):203-209.

18. Carney RM, Blumenthal JA, Stein PK, Watkins L, Catellier D, Berkman LF, Czajkowski SM, et al. Depression, heart rate variability, and acute myocardial infarction. Circulation. 2001;104(17):2024-2028. 